\title{
Developments in human growth hormone preparations: sustained-release, prolonged half-life, novel injection devices, and alternative delivery routes
}

REVIEW

\section{Yunpeng $\mathrm{Cai}^{1,2}$ \\ Mingxin $\mathrm{Xu}^{2}$ \\ Minglu Yuan ${ }^{2}$ \\ Zhenguo Liu' \\ Weien Yuan²}

'Department of Neurology, Xinhua Hospital, School of Medicine, ${ }^{2}$ School of Pharmacy, Shanghai Jiao Tong University, Shanghai, People's Republic of China
Correspondence: Weien Yuan School of Pharmacy, Shanghai Jiao

Tong University, 800 Dongchuan Road, Shanghai 200240, People's Republic of China

Tel +86 2I 34205072

$\mathrm{Fax}+862134205072$

Email yuanweien@।26.com

\section{Zhenguo Liu}

Department of Neurology, Xinhua

Hospital, Shanghai Jiao Tong University

School of Medicine, 1665 Kongjiang

Road, Shanghai 200092, People's Republic of China

Email zhenguoliu2004@aliyun.com
This article was published in the following Dove Press journal:

International Journal of Nanomedicine

25 July 2014

Number of times this article has been viewed
Abstract: Since the availability of recombinant human growth hormone (rhGH) enabled the application of human growth hormone both in clinical and research use in the 1980s, millions of patients were prescribed a daily injection of $\mathrm{rhGH}$, but noncompliance rates were high. To address the problem of noncompliance, numerous studies have been carried out, involving: sustained-release preparations, prolonged half-life derivatives, new injectors that cause less pain, and other noninvasive delivery methods such as intranasal, pulmonary and transdermal deliveries. Some accomplishments have been made and launched already, such as the Nutropin Depot $^{\circledR}$ microsphere and injectors $\left(\right.$ Zomajet $^{\circledR}$, Serojet ${ }^{\circledR}$, and NordiFlex ${ }^{\circledR}$ ). Here, we provide a review of the different technologies and illustrate the key points of these studies to achieve an improved rhGH product.

Keywords: intranasal, pulmonary, transdermal, microsphere, microneedle, hydrogel

\section{Introduction}

Human growth hormone ( $\mathrm{GH}$ or $\mathrm{hGH})$, also known as somatotropin or somatropin, is a 191-amino acid protein secreted by somatotropic cells of the anterior pituitary gland. Between 1957 and 1985, GH isolated from human cadaveric pituitaries was administered to children suffering from hormone deficiency. ${ }^{1}$ Due to the scarcity of resources, developing a synthesized form was imperative, but all attempts failed until 1979 when a recombinant hGH was developed, enabling large-scale commercial and research use.

Growth hormone is mainly used in medicine to treat children's growth disorders and adult growth hormone deficiency (GHD), with treatment beginning at a low dose and gradually titrated to obtain optimal efficacy while minimizing side effects. It is also approved for Turner syndrome, Prader-Willi syndrome, chronic renal insufficiency, idiopathic short stature in children, AIDS-related wasting, and fat accumulation associated with lipodystrophy in adults. In recent years in the United States, some doctors have prescribed growth hormone in GH-deficient older patients (but not healthy people) to increase vitality. Currently, recombinant human growth hormone ( $\mathrm{rhGH}$ ) is becoming prevalent for antiaging and body building, which raises concerns about abuse. However, rhGH is considered a very complex hormone, and many of its functions are still unknown.

Though it has been used for GH-deficiency patients for decades, hGH is not without drawbacks. One of the predominant drawbacks of hGH is its short plasma half-life, 3.4 hours after subcutaneous (SC) injection and 0.36 hours after 
intravenous (IV) injection. ${ }^{2}$ Generally, the administration of rhGH consists of daily SC injections or thrice-weekly intramuscular (IM) injections, which can be inconvenient and painful to patients. ${ }^{3}$

Noncompliance with daily injection may cause withdrawal of treatment, especially in children. Reports have suggested that inconsistency in growth hormone treatment is associated with reduced efficacy outcomes and increased health care costs, which occurs most in teenagers, with up to $23 \%$ of teenagers missing at least two injections per week. ${ }^{4}$ To address these problems, researchers have conducted numerous studies, which can be roughly divided into three directions: (i) develop long-acting preparations to lower the injection frequency, including new dosage forms, and modify the structure of rhGH to achieve a longer half-life; (ii) develop alternative delivery methods to avoid injections, including intranasal delivery, pulmonary delivery, and transdermal delivery; and (iii) novel injection devices.

Serum insulin-like growth factor-1 (IGF-1) is a good biochemical marker of rhGH action, and is used to evaluate the efficacy of rhGH preparations, with some limitations. ${ }^{5}$ Other biomarkers and parameters, such as insulin-like growth factor binding protein-3 level, body fat percentage, lipid profile, insulin sensitivity by homeostasis model assessment, quantitative insulin check index, and thyroid function, are alternatives used in more comprehensive pharmacological experiments. ${ }^{6-8}$

rhGH is a blockbuster drug, holding a market of several billions of dollars, so it is imperative to develop a better preparation to address the aforementioned problems.

\section{Long-acting preparations}

Long-acting preparations can lower the injection frequency directly, at an interval range of 1 week to longer than 1 month. Although endogenous hGH is secreted as multiple daily pulses, unlike continuous release or daily injection of rhGH preparations, there is no difference in the efficacy or tolerability. ${ }^{7}$ Therefore, a long-acting preparation is preferable to improve the noncompliance of patients. Generally, there are two methods for creating long-acting preparations. One forms reversible complexes which stabilize hGH, such

Table I Summary of different technological advancements of rhGH preparations

\begin{tabular}{|c|c|c|}
\hline Strategy & Advantages & Disadvantages \\
\hline \multicolumn{3}{|l|}{ Sustained-release } \\
\hline Zinc-complex & Easily performed; can be adopted in other studies & Limited improvement on prolonging release time \\
\hline Microsphere ${ }^{78}$ & $\begin{array}{l}\text { Easily prepared; commercially available for many } \\
\text { materials }\end{array}$ & $\begin{array}{l}\text { Acidic degradation of PLGA } \\
\text { denaturation of rhGH }\end{array}$ \\
\hline Hydrogel & $\begin{array}{l}\text { Long and adjustable sustained-release; } \\
\text { easily prepared }\end{array}$ & $\begin{array}{l}\text { Adverse effect at injection site; shorter sustained- } \\
\text { release time than microspheres }\end{array}$ \\
\hline \multicolumn{3}{|l|}{ Prolonged half-life } \\
\hline PEGylation & $\begin{array}{l}\text { Reduced clearance; adjustable half-life based on } \\
\text { PEGylated site }\end{array}$ & $\begin{array}{l}\text { Initial burst (some studies have addressed this); } \\
\text { storage problem in the solution state }\end{array}$ \\
\hline Albumin conjugation & I3-I5 h half-life in monkeys & $\begin{array}{l}\text { Possible adverse event such as lipoatrophy; } \\
\text { feasibility of scale-up }\end{array}$ \\
\hline XTEN amino sequence fusion & I I0 h half-life in monkeys & May alter the potency of rhGH \\
\hline Hybrid Fc fusion & High bioavailability & \\
\hline Carboxy-terminal peptide fusion & $\begin{array}{l}\text { No adverse effect observed } \\
\text { I month efficacy in human B lymphocytes }\end{array}$ & Low bioavailability \\
\hline Extracellular receptor of hGH fusion & $\begin{array}{l}\text { I week efficacy has been demonstrated in a } \\
\text { Phase II trial; } 10 \mathrm{~d} \text { effect in rats }\end{array}$ & Further study in animal model required \\
\hline Intranasal delivery & $\begin{array}{l}\text { Noninvasive; can mimic endogenous pulsatile } \\
\text { hGH secretion pattern }\end{array}$ & $\begin{array}{l}\text { Possible scale-up production problem; } \\
\text { damage to nasal mucosa }\end{array}$ \\
\hline \multicolumn{3}{|l|}{ Transdermal delivery } \\
\hline Radio-frequency ablation & Relative high bioavailability ( $75 \%$ in rats); less pain & $\begin{array}{l}\text { Damage to the epidermis } \\
\text { complexity as for a chronic disease }\end{array}$ \\
\hline Microneedle patch & Less pain; easily prepared & Possible local site redness and swelling \\
\hline Self-dissolving micropiles & Self-administration & $\begin{array}{l}\text { Low bioavailability (except } \mathrm{N} \text {-trimethyl chitosan } \\
\text { chloride) }\end{array}$ \\
\hline Pulmonary delivery & Noninvasive; self-administration & $\begin{array}{l}\text { Surgery needed to insert under skin; } \\
\text { loss of drug during delivery process } \\
\text { (bioavailability lower than } 50 \% \text { in most cases); } \\
\text { dose accuracy related to inhalation pattern }\end{array}$ \\
\hline Novel injection devices & Less pain; self-administration & Expensive device \\
\hline
\end{tabular}


as zinc-hGH complex. The other one fabricates sustainedrelease preparations, entrapping hGH into matrixes, like microspheres and hydrogels.

\section{Zinc complexes}

Zinc can be applied to stabilize hGH, for two $\mathrm{Zn}^{2+}$ ions can associate per dimer of $\mathrm{hGH}$ in a cooperative fashion. The $\mathrm{Zn}^{2+}$ hGH dimer was more stable than monomeric hGH to denaturation in guanidine- $\mathrm{HCl}$, and it was irreversible. ${ }^{9}$ Formation of a $\mathrm{Zn}\left(2^{+}\right)$-hGH dimeric complex may be important for storage of hGH in secretory granules. Also, the binding affinity of hGH for the extracellular binding domain of the hPRL receptor could be increased about 8,000-fold by addition of 50 micromolar $\mathrm{ZnCl}_{2}{ }^{10}$ Though this method did not improve the half-life of rhGH tremendously, it was widely used in later studies as a complementary way to stabilize $\mathrm{hGH}$, and typically got better results compared with other no-zinc formulations.

\section{Microspheres/microparticles}

The only once-commercially available rhGH long-acting preparation was poly(lactic-co-glycolic acid) (PLGA) microsphere. Nutropin Depot ${ }^{\circledR}$ (Genentech, Inc., South San Francisco, California, USA) was developed as a biodegradable microsphere form of $\mathrm{rhGH}$, achieving a 1-month sustained-release. ${ }^{11}$ Twice-monthly administration is recommended for children only. Mainly adverse events related to the injection site, included nodules (60\% of injections), erythema (54\%), and postinjection pain (36\%) in 1,483 injections. ${ }^{8}$ For individuals exceeding $30 \mathrm{~kg}$, multiple injections were required, mainly attributed to its low loading amount of rhGH (only 15\% by weight). ${ }^{12}$ First launched in 1999 in the United States, this formulation was commercially discontinued in 2004 for manufacturing problems such as scale up (one patch of $500 \mathrm{~g}$ microspheres cost 2 weeks). ${ }^{13}$ According to its official announcement, it was due to "the significant resources required by both companies to continue manufacturing and commercializing the product". ${ }^{14}$

Beside Nutropin $\operatorname{depot}^{\circledR}$, many other studies on microspheres were conducted in last two decades. Kwak et al fabricated a PLGA microsphere named DA-3003 of rhGH, with zinc oxide and hydroxypropyl- $\beta$-cyclodextrin as the release modulator, and sustained-release lasted for 14 days in rats and 28 days in monkeys. ${ }^{15}$ But it had a limited loading amount of $13 \% \pm 3 \%$ and demonstrated a low bioavailability of $\mathrm{rhGH}(21 \%$ in rats and $30 \%-49 \%$ in monkeys). Johnson et al developed PLGA microspheres loaded with zinc-rhGH by using spray drying in liquid nitrogen. ${ }^{16}$ Elevated serum rhGH lasted for 1 month in rats and monkeys. However, the loading amount of zinc-rhGH was lower than $6 \%$ in the formulation. Kim et al prepared porous PLGA microsphere with Pluronic ${ }^{\circledR}$ F127 as the porogen and incorporated rhGH into it, and then closed the pores in an ethanol vapor phase using a fluidized bed reactor. ${ }^{17}$ The loading amount was $7.0 \%$, and sustained-release lasted for over 1 month.

Besides PLGA, other novel materials were also adopted to fabricate microspheres, realizing sustained-release and protecting the sensitive rhGH as well. Vlugt-Wensink et al developed hydroxyethyl methacrylated dextran microspheres of rhGH to avoid the drawbacks of PLGA: ${ }^{18}$ the acidification of PLGA can cause aggregation of protein, and hydrophobic PLGA is unfriendly to sensitive protein. However, the synthesis was complicated, and larger-scale preparation induced more variants which made the microsphere characteristics uncontrollable.

Lee et al developed a PLGA microsphere of rhGH with the precipitation method, a nonaqueous cryogenic process to avoid a water-organic interface. ${ }^{19}$ The sustained-release lasted from 3 weeks to 90 days. Loading amounts were all 15\% (weight/weight [w/w]).

Poly(monomethoxypolyethylene glycol-co-D,L-lactide) (PELA) was applied to fabricate microspheres for increased sustained-release effects of rhGH without any exogenous stabilizing excipients. ${ }^{20}$ PELA microspheres exhibited the advantages of a relatively high loading amount $(5.72 \%)$, low initial burst (14.2\%), and stability of rhGH over PLA and PLGA

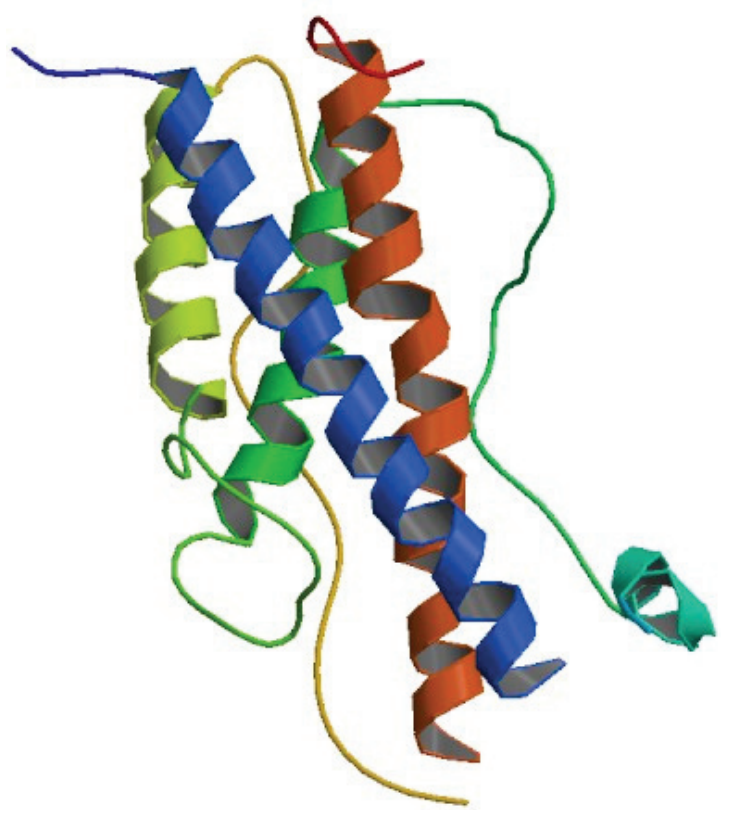

Figure I Three-dimensional structure of human growth hormone. Notes: Reproduced from Chantalat L, Jones ND, Korber F, Navaza J, Pavlovsky AG. The crystal-structure of wild-type growth-hormone at 2.5 angstrom resolution. Protein Pept Lett. 1995;2:333-340. ${ }^{79}$ 
Table 2 Clinical trials of rhGH development in recent years

\begin{tabular}{|c|c|c|c|}
\hline Name & Category & Sponsor & $\begin{array}{l}\text { Current state } \\
\text { of clinical trials }\end{array}$ \\
\hline PEGylated somatropin & Prolonged half-life/PEGylation & GeneScience Pharmaceuticals Co., Ltd. & Phase III in 20II \\
\hline PEGylated-somatropin & Prolonged half-life/PEGylation & Xiamen Amoytop Biotech Co. Ltd. & Phase I in $201 \mathrm{I}$ \\
\hline MOD-4023 & Prolonged half-life/fused with carboxy-terminal peptide & Prolor Biotech, Inc. & Phase II in 2010 \\
\hline VRS-3I7 & Prolonged half-life/fused with XTEN amino sequence & Versartis, Inc. & Phase I in $20 \mathrm{II}$ \\
\hline ACP-00I & Prolonged half-life & Ascendis Pharma A/S & Phase II in 2010 \\
\hline ALTU-238 & Sustained-release/crystalline formulation & Altus Pharmaceuticals, Inc. & Phase II in 2006 \\
\hline LB03002 & Sustained-release/sodium hyaluronate microparticles & LG Life Sciences & Phase IV in 2012 \\
\hline NNC0195-0092 & Prolonged half-life/albumin conjugation & Novo Nordisk A/S & Phase I in 2012 \\
\hline $\mathrm{NNCl} 26-0083$ & Prolonged half-life/PEGylation & Novo Nordisk A/S & Phase II in 2009 \\
\hline hGH-ViaDerm ${ }^{\text {TM }}$ System & Transdermal & Teva Neuroscience, Inc. & Phase I in 2007 \\
\hline PHA-794428 & Prolonged half-life/PEGylation & Pfizer, Inc. & Phase II in 2006 \\
\hline
\end{tabular}

Note: Data source: $\underline{h t t p: / / c l i n i c a l t r i a l s . g o v . ~}$

Abbreviations: rhGH, recombinant human growth hormone; hGH, human growth hormone; PEG, polyethylene glycol.

microspheres. The PELA could self-assemble into microspheres on the biphasic interface, avoiding any surfactant.

An amphiphilic copolymer, poly(lactide-co-glycolide)grafted dextran, is used as both an emulsifier in the water/oil emulsion and a matrix of the microspheres of rhGH to protect the protein from the water/oil interface since the amphiphilic copolymer aligned at the interface. ${ }^{21}$ The plasma concentration of rhGH was maintained for 1 week in mice with a loading amount of $10 \%$.

Kim et al developed a sustained-release formulation of rhGH using sodium hyaluronate microparticles with spray drying, and named it LB03002 (LG Life Sciences, Seoul, Korea). ${ }^{22}$ LB03002 was an injectable rhGH suspension of microparticles in which rhGH was incorporated into sodium hyaluronate at the optimized ratio of 1:3 (loading efficiency of $25 \%$ ). rhGH release from microparticles could last for 72 hours and elevate IGF-1 level for 6 days in Beagle dogs. However, serum concentration in monkeys was only elevated for less than 30 hours. The small particle size (about $5 \mu \mathrm{m}$ ) means it can be injected using a 26 gauge needle. In later studies, LB03002 validated its efficacy in both children and adults with GHD. Serum rhGH concentration remained above the limit of detection for 3 days and IGF-1 was elevated for 5 days, demonstrating its potential to be a weekly product. ${ }^{23,24}$

Other technologies have also been employed to fabricate rhGH polymeric microparticles. To encapsulate rhGH into polymers while keeping its integrity and bioactivity, supercritical carbon dioxide fluid was employed..$^{25}$

Protein crystallization can also be an alternative choice, since insulin was manufactured as crystalline form and achieved 24-hour sustained-release. Govardhan et al developed a crystalline form of rhGM and coated it with poly(arginine) to prolong its dissolution profile by 1 week in rats. ${ }^{26}$ It contained $>80 \mathrm{wt} \%$ of $\mathrm{rhGH}$, had low viscosity $(5 \mathrm{cP})$, and was easily injected through fine needles (29-31 gauge). However, crystallization did not prolong the dissolution time much (about 1 day); the sustained-release of 1 week was mainly attributed to the opposite charged poly-(arginine) coating on its surface.

There are several disadvantages to PLGA microspheres, such as low loading efficiency, high initial burst release, delay of release after the initial burst, protein aggregation, denaturation, hydrophobic surface of microsphere, and an acidic microenvironment. ${ }^{27}$ Though solutions to these problems have been addressed or alleviated in other experiments, for rhGH microspheres a collective solution has not been put forward yet.

Most importantly, the loading amount of rhGH is a critical parameter to the application of sustained-release of rhGH. Though the dose of hGH may vary from person to person, beginning from $0.1 \mathrm{mg} /$ day to $6 \mathrm{mg} /$ day, the loading amount needed can be roughly estimated. A single injection of the once-weekly injection formulation would be required to deliver 11-18 mg of rhGH for an estimated child's maximum body weight of $60 \mathrm{~kg}$. Based on the assumption of a desirable maximum vehicle volume for SC injection to be $1 \mathrm{~mL}$, the concentration of rhGH in the injection vehicle should be $11-18 \mathrm{mg} / \mathrm{mL}$. In cases of Nutropin Depot ${ }^{\circledR}$, the concentration of PLGA microsphere suspensions is $105.5 \mathrm{mg} / \mathrm{mL} .{ }^{22}$ To deliver the maximum amount, the loading efficiency should be $17.1 \%$ or more. Although we can inject more volume to make up the scarcity of rhGH in low-loading efficiency formulations, adverse events such as nodules may be triggered more frequently as a result.

To sum up, a desirable microsphere of rhGH should be safe and efficient. For PLGA microspheres, this means overcoming the denaturation by hydrophobic interaction and/or harsh acidic microenvironment associated with the degradation of PLGA, a small and uniform particle size which can be easily injected through fine needles (29-31 gauge), and a high 


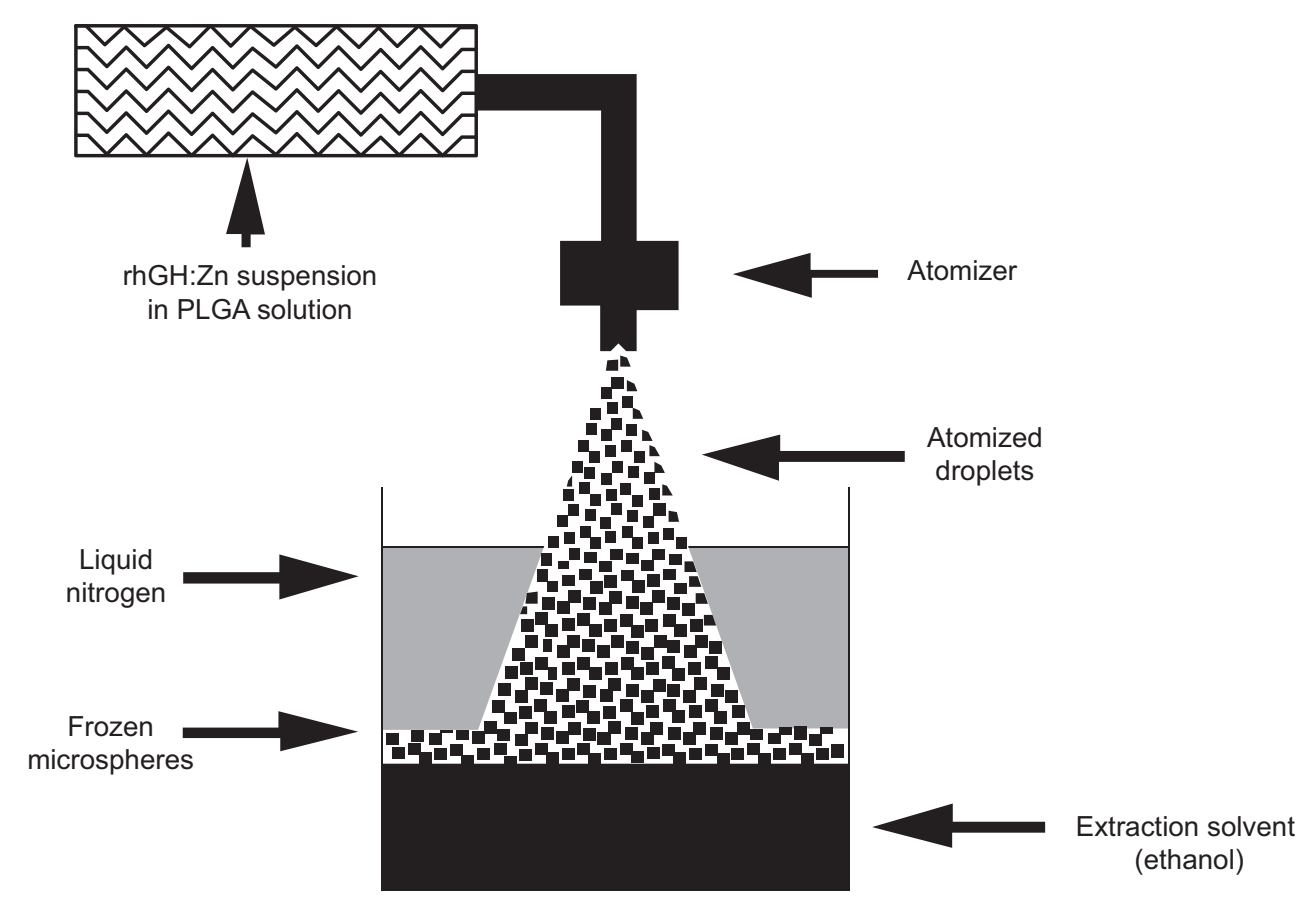

Figure 2 Preparation of rhGH microspheres by an atomizer.

Notes: Reprinted from Pharmaceutical Research, 14(6), 1997, pages 730-735, The stabilization and encapsulation of human growth hormone into biodegradable microspheres, Johnson OL, Jaworowicz W, Cleland JL, et al, Figure I. ${ }^{16}$ With kind permission from Springer Science and Business Media. Copyright $\odot$ I 997 , Plenum Publishing Corporation. The rhGH:Zn complex was suspended in dichloromethane containing PLGA polymer. The suspension was atomized by an ultrasonic nozzle and frozen by liquid nitrogen. After the evaporation of liquid nitrogen, the ethanol melted and extracted dichloromethane from the microspheres, which were then filtered and dried.

Abbreviations: PLGA, poly(lactic-co-glycolic acid); rhGH, recombinant human growth hormone.

loading efficiency of more than $17 \%$. Other new materials may have advantages over PLGA, but further study should be conducted to validate their safety and feasibility.

\section{Hydrogel}

To achieve a sustained-release, a thermo-responsive and photo-crosslinkable in situ pluronic/chitosan gelation of rhGH was prepared by UV irradiation of the physical gels above their gelation temperatures. ${ }^{28}$ Results showed a 20-day sustained-release in vitro, attributable to the highly crosslinked structure.

Katakam et al developed a gel depot of rhGH with Poloxamer 407, and tested it in breed dogs by SC injection, demonstrating its sustained release for 132 hours. ${ }^{29}$ Poloxamer 407 exhibits property as reverse thermal gelation that existing as a mobile viscous liquid at low temperatures (room temperature), but forming a rigid semisolid gel at higher temperatures (body temperature). However, this gel depot showed an undesirable high initial burst more than 10 -fold of the therapeutic window, which could be detrimental to patients.

Poly(ethylene glycol) modified with fluorocarbon end groups was applied to form in situ transition hydrogel of rhGH by hydrophobic interaction of the end groups. ${ }^{30}$ The mechanism of phase transition was that organic solvent (N-methyl pyrrolidone) diffused into the surrounding areas.
In vitro characterization showed a sustained-release of more than 2 weeks. Further studies are needed to be conducted in vivo.

A poly(ethylene glycol)-poly(L-alanine-co-Lphenylalanine) aqueous solution was developed as a thermosensitive gel. ${ }^{31}$ This solution can be stable for storage as a ready-to-use formulation. Results in rats showed marginal tissue inflammation, and the gel was eliminated in 15 days.

A thermosensitive poly(organophosphazene) hydrogel combined with polyelectrolyte complex (PEC), which was to suppress diffusion of rhGH from the hydrogel through an enlargement of the hydrodynamic size of $\mathrm{rhGH}$, was proposed as a sustained-release system of zinc-rhGH complex. ${ }^{32}$ Results of pharmacokinetic study in rats demonstrated a sustained-release of rhGH for 5 days and $t_{1 / 2}$ of about 20 hours. Further studies for the bioactivity of released rhGH and more animal models are required to evaluate. A similar study conducted by the same group combining negatively charged rhGH with cationic polymer-protamine, also suppressed the release of rhGH from hydrogel. Results showed a plasma rhGH level until 5 days in rats and elevated plasma level of IGF-1 until 13 days in monkeys, which was comparable to rhGH daily injection for 7 days. Recently they improved this hydrogel by combining their previous two studies - both the positively charged PEC and the negatively 
charged protamine sulfate - to form a dual ionic interaction system. ${ }^{33}$ Data suggested the PEC-loaded anionic hydrogel for a 4-day release of rhGH with a similar area under the curve compared to rhGH solution, and a significantly increased growth rate compared to daily injection of $\mathrm{rhGH}$ solution for 7 days in hypophysectomized rats.

Certainly, there are drawbacks of hydrogel, which are mainly attributed to its hydrophilic property. The initial burst and short sustained-release period are the two most common issues, as well as shelf storage time. The loaded protein drugs can be released rapidly during the initial release period by diffusion due to their hydrophilicity and small hydrodynamic sizes. ${ }^{34}$

\section{Other long-acting formulations}

PLGA solution can be used as a sustained-release depot directly; the dynamics of phase inversion control the release of drug. In one study, benzyl benzoate/PLGA solution depot realized a 28-day sustained-release in rats, and rhGH particles were suspended at a level of $10 \%$ by weight. ${ }^{35}$

PLGA laminar implant formulation $(10 \% \mathrm{w} / \mathrm{w})$ was prepared for sustained-release, and compared with the conventional commercial injectable (Norditropin ${ }^{\circledR}$ ) in rats. ${ }^{36}$ Results suggested it was effective for 15 days and more potent than
Norditropin ${ }^{\circledR}$. However, the surgery needed to implant this laminar device may limit its application, since it is more complicated than injection.

\section{Extending half-life of $\mathbf{h} \mathbf{G H}$}

As mentioned in the Introduction section, hGH only has a short half-life of 3.4 hours after SC injection, so extending its half-life by structure modification or conjugation can lower the injection frequency as well. Though it may alter the potency of $\mathrm{hGH}$, for example by lowering the affinity to the receptor, prolonging the half-life of hGH can increase the exposure time to the tissues, thus reinforcing its potency.

Among a host of modification methods, PEGylation has become a widely used strategy to extend the half-life of hGH; this method avoids its uptake by the reticuloendothelial system and reduced clearance by filtration in the kidneys. ${ }^{37}$ De Schepper et al developed another PEGylated rhGH called NNC126-0083 to attain a onceweekly preparation. ${ }^{37}$ Lipoatrophy was not observed in 30 children, but further research was required to ensure its safety by testing it in adults and more subjects. However, the IGF-1 profile was not satisfactory, since the response began subsiding 3 days after injection, rather than lasting for 1 week as planned.

A
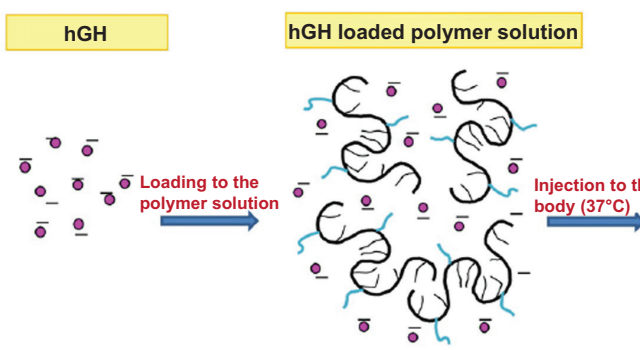

B
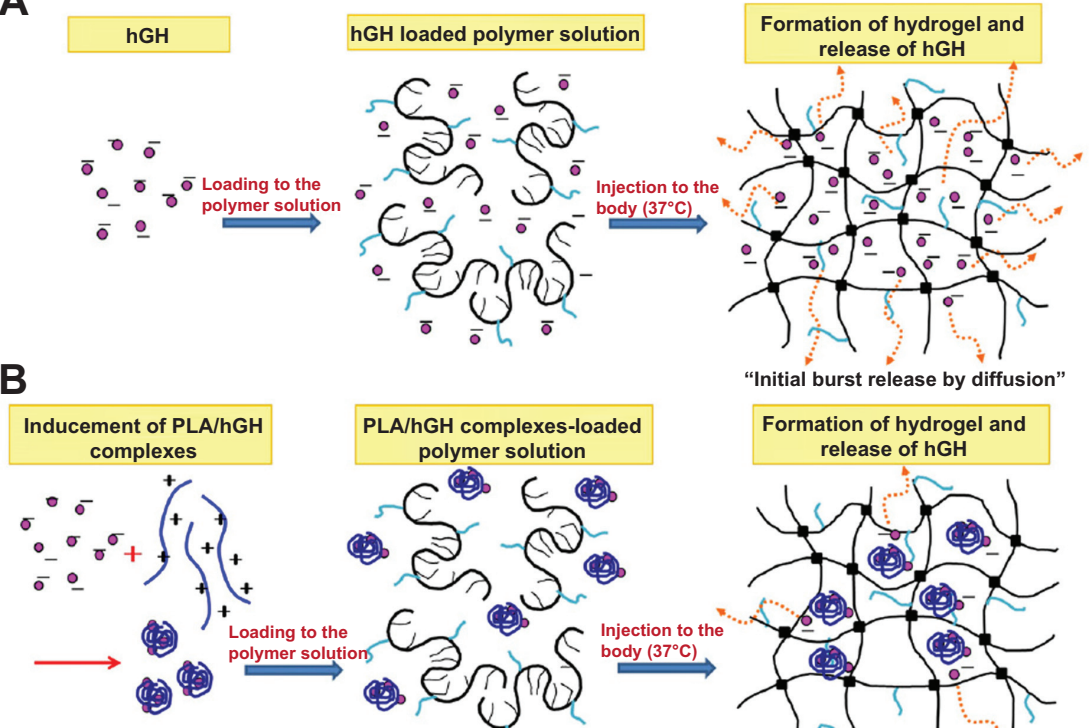

Formation of hydrogel and polymer solution
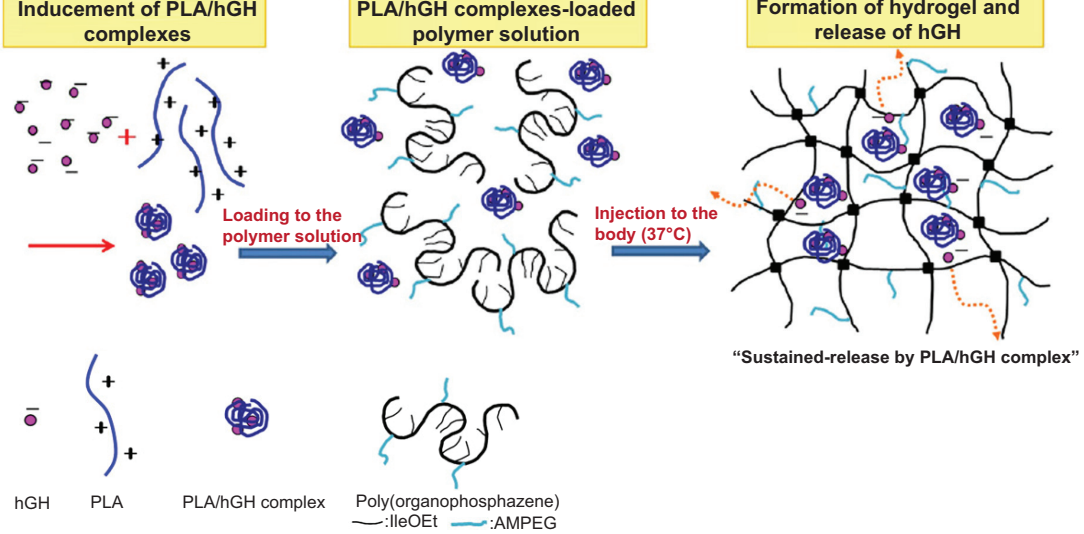

"Sustained-release by PLA/hGH complex"

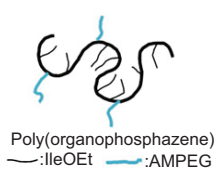

Figure 3 Schematic illustrations of different release behaviors of rhGH from rhGH alone loaded hydrogel (A) and PLA/rhGH complex-loaded hydrogel (B), which can inhibit the initial burst.

Note: Reprinted from Journal of Controlled Release, I47(3), Park MR, Chun C, Ahn SW, Ki MH, Cho CS, Song SC, Sustained delivery of human growth hormone using a polyelectrolyte complex-loaded thermosensitive polyphosphazene hydrogel, pages 359-367.32 Copyright @ 20I0, with permission from Elsevier.

Abbreviations: PLA, poly(lactic acid); hGH, human growth hormone; rhGH, recombinant human growth hormone. 
More studies of PEGylation were conducted, such as PHA-794428, ${ }^{2}$ not only for prolonging half-life of hGH, but also to confirm whether hGH can be a good protein model to verify new PEGylation technology. ${ }^{2,38-43}$ Many of them had achieved a longer half-life, similar or better efficacy, and higher bioavailability. However, the key issues were the safety and scale-up of production. A Phase II trial in GHD patients revealed the risk of lipoatrophy at the injection site of PEGylation of rhGH, which terminated further clinical trials. ${ }^{44}$ The pathology is still unknown, though it was possible that its delayed absorption due to high molecular weight led to this adverse effect; the PEG-rhGH concentrations did not vary between lipoatrophy and nonlipoatrophy patients. Its prevalence in female patients might have been due to more adipose tissue in women, although a sex-specific response was not ruled out.

Experiments to conjugate rhGH with albumin were conducted early in 1988; the conjugation could eliminate the renal clearance, but improvement was not obvious. ${ }^{45}$ Osborn et al developed albutropin, a fusion of rhGH and human serum albumin at its N-terminus. ${ }^{46}$ After SC dosing, it exhibited a sixfold longer terminal half-life (13-15 hours) than rhGH in monkeys. However, SC only had a poor bioavailability of $7.9 \%$, compared with $3.6 \%$ of rhGH in SC dosing.

Cleland et al fused rhGH with a special amino sequence called XTEN at the N-terminus and C-terminus to obtain a novel protein with a long half-life and high potency in vivo. ${ }^{47}$ Though this modification reduced the affinity with receptors by elevenfold, the prolonged exposure time achieved a greater potency. In monkeys, this new compound, named VRS-317, had a terminal elimination half-life of 110 hours, exhibited a high bioavailability of about $100 \%$, and was well tolerated with no observed adverse effects after every other week SC dosing for 14 weeks. VRS-317 also did not cause lipoatrophy in pig and monkey studies. Probably because of its low affinity with local receptors, after SC injection patients avoided lipoatrophy.

In another study, rhGH was fused with a hybrid Fc fragment containing partial Fc domains of human $\operatorname{IgD}$ and IgG4 to prolong its acting time. ${ }^{48}$ The fusion protein, rhGHhyFc, increased the diameter of rhGH from $5 \mathrm{~nm}$ to $11 \mathrm{~nm}$. To perform the controlled release, a diblock copolymer nanopore membrane (average pore size of $14.3 \mathrm{~nm}$ ) was employed with a titanium reservoir. Results exhibited a 1 month effect of triggering the phosphorylation of Janus kinase 2 in human B lymphocyte.

ACP-001 was designed as a long-acting prodrug that linked to a carrier, which released the rhGH over a defined period of time. ACP-001 was safe and well tolerated in a
Phase II study in adult patients with GHD. Pharmacokinetic results supported once-weekly dosing. ${ }^{49}$

A new compound named MOD-4023 fused the carboxyterminal peptide of human chorionic gonadotropin with $\mathrm{rhGH}$ to generate a weekly long-acting rhGH. ${ }^{50}$ The Phase II study has been accomplished, which suggested its effectiveness and safety in 39 GHD patients. In two cohorts (45\% and 100\% of each patient's cumulative weekly rhGH dose) the mean IGF-1 values were comparable to those obtained with daily rhGH at steady state.

A novel approach that fused rhGH with an extracellular receptor at the $\mathrm{N}$-terminus was proposed, and a single injection promoted growth for 10 days in rats. ${ }^{51}$ The fusion protein can either bind to itself or in a head-to-tail reciprocal dimer. In the dimer configuration, the ligand is protected from breakdown and a dynamic equilibrium is established between protected and unprotected ligands. In the unprotected form, the ligand can bind to the cell receptor and activate the signal of cells. The dynamic equilibrium between the protected and unprotected form can prolong the acting time of hGH and protect it from clearance.

In summary, structure modification and conjugation can prolong the half-life of hGH to several weeks readily. How-
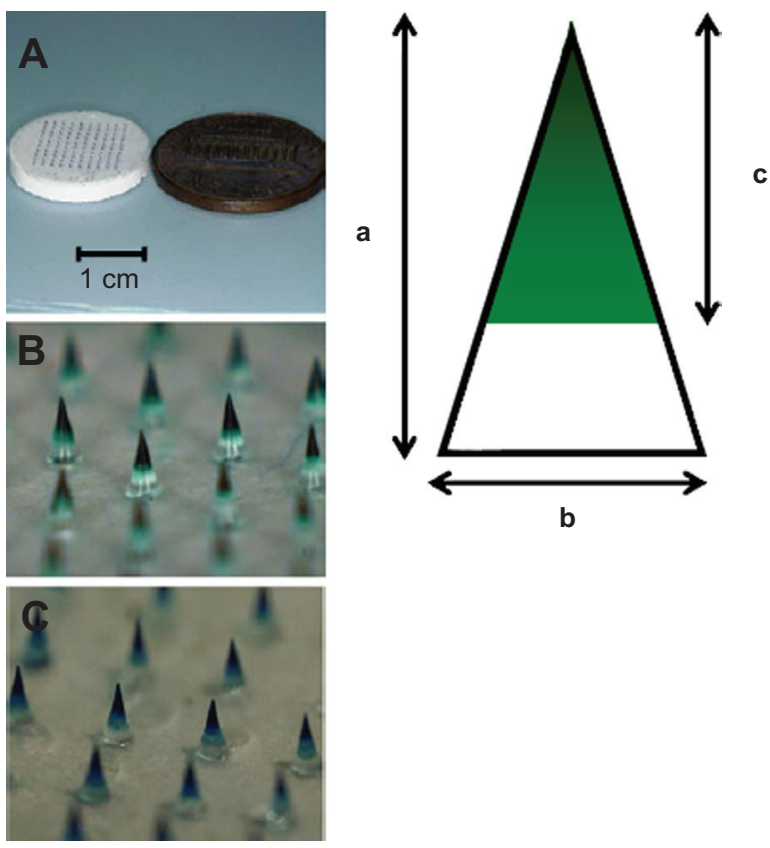

Figure 4 Dissolving microneedles made of chondroitin sulfate as the base used in the in vivo rat absorption studies.

Notes: (A) An overview of the microneedle patch. (B) rhGH chondroitin sulfate dissolving microneedles. (C) DDAVP chondroitin dissolving microneedles. The inserted schema shows the following length: (a) whole length, (b) diameter of the basement, and (c) length of the drug loaded space. Adapted from Springer and Pharmaceutical Research, 28(I), 20I I, pages 7-2I, Two-layered dissolving microneedles for percutaneous delivery of peptide/protein drugs in rats, Fukushima K, Ise A, Morita H, et al, Figure I, copyright (C) 2010 Springer, with kind permission from Springer Science and Business Media. ${ }^{65}$

Abbreviations: DDAVP, desmopressin acetate; rhGH, recombinant human growth hormone. 
ever, the worry of safety has become a major issue, since side effects in PEGylation of hGH were demonstrated in clinical trials. This concern may also apply to other modified hGH molecules. Also, new synthetic routes can increase the difficulty in mass production; researchers should also validate their works in pilot scale.

\section{Alternative delivery systems}

Apart from traditional SC and IM injections, other delivery routes, both invasive and noninvasive, are available. Noninvasive routes, such as intranasal, pulmonary, and part of the transdermal delivery, are painless and easily performed. Therefore, self-administration by patients can mimic the endogenous pulsatile pattern of hGH secretion, which might be of importance for the induction of growth and other hGH actions. The main task found in studies is how to deliver a sufficient amount of $\mathrm{hGH}$ in patients, given the loss during the permeation of mucous membrane, the travel to the lung, and the penetration of stratum corneum.

\section{Intranasal delivery}

Early in 1990, Baldwin et al had tested the effect of sodium tauro-24,25-dihydrofusidate on the promotion of nasal absorption of rhGH in three animal models: rat, rabbit and sheep. ${ }^{52}$ Though higher bioavailability was observed compared with control group, it had an extremely low bioavailability (1.6\%-3.0\%) compared with SC injection in later human experiments. ${ }^{53}$

In a similar study, rhGH and 1- $\alpha$-phosphatidylcholine (LPC) were administered to rats (bioavailability up to $17.5 \%$ ), rabbits $\left(72.8 \%\right.$ ), and sheep (up to $16 \%$ ), respectively. ${ }^{54}$

In other research, polyoxyethylene 9-lauryl ether (laureth-9) promoted permeation remarkably in rats, but histological changes in the nasal mucosa of rats treated with $1 \%$ laureth-9 were severe. ${ }^{55}$ Didecanoyl-L$\alpha$-phosphatidylcholine (DDPC) in humans showed a low bioavailability of $3.8 \%-8.9 \%$, and thus was of limited value for the induction of a metabolic response. ${ }^{56}$ Formulations containing $\alpha$-cyclodextrin and DDPC demonstrated a bioavailability of $20 \%$ in rabbits, but severe damage to the nasal epithelial membrane was also observed. ${ }^{57}$

Formulations of chitosan and rhGH mixture, in powder and granule forms, achieved bioavailability of $14 \%$ and $15 \%$, respectively, in sheep. ${ }^{58}$ Moreover, its effect on the integrity of nasal membrane proved to be minimal in rats. ${ }^{59}$ The mechanism of effect of the chitosan was suggested to be a combination of bioadhesion and a transient widening of the tight junctions in the membrane. Therefore, minimal damage to the membrane could be attained with chitosan and its derivatives.

More recently, N-trimethyl chitosan chloride (TMC) was employed for nasal administration, and a patented fatty acid-based delivery system named Pheroid was compared as an enhancer as well. ${ }^{60}$ Results showed extremely high bioavailability of Pheroid vesicle and TMC H-L (high molecular weight with low degree of quaternization) in rats, $128.5 \%$ and $136.1 \%$, respectively.

The potential of using bioadhesive microspheres as a nasal delivery system was investigated in sheep, with surfactant LPC and microsphere alone. ${ }^{61}$ Both rhGH solution for nasal delivery and SC injection were compared. Results showed promoted effects of microsphere and microsphere with LPC, and bioavailability was $2.7 \%$ and $14.4 \%$, respectively, related to SC injection. However, damage to the mucosa was observed probably due to the presence of LPC.

Leitner et al developed a nasal microparticulate delivery system with thiomer polycarbophil-cysteine, for its permeation-enhancing properties combined with mucoadhesive and enzyme-inhibitory properties, and evaluated it in rats. ${ }^{62}$ Formulation with glutathione as the permeation mediator achieved a relative bioavailability of $8.1 \%$ compared with SC injection and a prolonged release time for several hours.

In summary, intranasal delivery shows priorities as a noninvasive delivery system and can be performed by patients at home. However, to delivery rhGH effectively, promoting agents such as surfactant materials and bile salts are necessary, which can damage the nasal membrane. For some other enhancers such as cyclodextrins, chitosan and selected phospholipids (eg, LPC), the absorption-enhancing effect was reported to be fine without much irritation to the mucosa. Still, further clinical trials should be conducted to estimate the safety in long-term use. Besides, given the common lower bioavailability of rhGH compared to that of SC injection, higher loading efficiency is required than conventional injections.

\section{Transdermal delivery}

Small microchannels created by radiofrequency ablation can be highly amenable to the transdermal delivery of watersoluble drugs into the systemic circulation. To enhance the rhGH transport, this technology was applied on rats and guinea pigs. ${ }^{63}$ Results showed a bioavailability of $75 \%$ (rats) or $33 \%$ (guinea pigs) relative to $\mathrm{SC}$ injection with plasma profiles resembling that of SC injection. Elevated levels of systemic IGF-1 were also observed. The tolerability, safety, and pharmacology of this system were tested in a 
Phase I clinical trial in adults in 2007 (ClinicalTrials.gov identifier: NCT 00455260).

The microneedle (percutaneous delivery) is an alternative method for transdermal delivery, combining convenience and safety. This technology has been proposed for decades, but not until the 1990s was it applied due to manufacturing difficulties.

In recent research, rhGH was encapsulated in $600 \mu \mathrm{m}$ long microneedles composed of carboxymethylcellulose and trehalose, which could be dissolved in body fluid, using an aqueous, moderate-temperature process ${ }^{64}$ Data in wild-type male hairless rats demonstrated $71 \%$ absolute bioavailability of rhGH at an administration dose of about $170 \mu \mathrm{g}$, where the remaining rhGH was mostly accounted for in the patch due to incomplete dissolution of microneedles. Treatment with dissolving microneedles only caused slight and transient erythema. The skin barrier stayed open for up to 2 days after patch removal, which was probably due to the residual microneedle matrix in the skin.

A two-layered dissolving microneedle was developed, with water-soluble thread-forming biopolymers used as the base. ${ }^{65}$ The rhGH was formulated as a solid dispersion. After the insertion of a dissolving microneedle into the skin, the base immediately dissolved and then rhGH was released. Data showed a highest absolute bioavailability of $101.3 \% \pm 9.2 \%$ for chondroitin-dissolving microneedles among different base formulations.

Self-dissolving micropiles (SDMP) as a transdermal delivery system of rhGH were studied in rats, with dextran used as a base. ${ }^{66}$ After mixing dextran solution with rhGH, SDMPs were prepared by pulling the mixture with polypropylene tips. SDMPs were inserted into the rat skin at a dose of $200 \mu \mathrm{g} / \mathrm{kg}$, and by comparing with IV injection of rhGH solution ( $5 \mu \mathrm{g} / \mathrm{kg}$ ), bioavailability of rhGH from SDMP was calculated to be $87.5 \%$.

Transdermal delivery exhibits high availability, which can emulate SC injection. The microneedle is the most developed transdermal delivery, and will hopefully be launched as a transdermal delivery method. Most of the transdermal methods mentioned above involve some pain. Redness and swelling at the administration site can be seen in some patients. But it is still a better choice over conventional injection, once the efficacy is validated in clinical trials.

\section{Pulmonary delivery}

In the early stage of pulmonary delivery studies, rhGH was instilled directly into the lower respiratory tract and shown to be biologically active after passage through the lungs in adult rats, having a mean absolute bioavailability of approximately $36 \%$ and demonstrating the potential of the lungs to be an administration route for $\mathrm{hGH}^{.67,68}$ Also, they found there was a tendency towards saturation as the instilled dose increased. Another experiment found that aerosol of rhGH solution can achieve a higher bioavailability (45\%) than that of instillate (16\%) compared with IV injection in rabbits, which was attributed to the differential effects of mucociliary clearance. ${ }^{69}$

A later experiment investigated the properties of a $\mathrm{rhGH}$ dry powder inhaler, due to the improved stability of the dry state..$^{70}$ The formulation consisted of dipalmitoylphosphatidylcholine, the pricipal component as lung surfactant, lactose and rhGH, and was prepared by spray-drying. Results showed a primary particle diameter of $4.4 \mu \mathrm{m}$ and a tap density of $0.069 \mathrm{~g} / \mathrm{cm}^{3}$.rhGH absorbed into the bloodstream with an absolute bioavailability of $23 \%$ and $8 \%$ following intratracheal insufflation of the dry powder and intratracheal sprayinstillation of a solution of the hormone, respectively.

Recently, 22 GH-deficient children aged $6-16$ years old were treated with rhGH inhalation powder..$^{71}$ Absorption of rhGH appeared to be faster after inhalation, with maximum serum concentrations measured at 1-4 hours compared with 2-8 hours for SC injection. Mean relative bioavailability for inhaled rhGH was $3.5 \%$ and mean relative biopotency, based on IGF-1 response, was 5.5\%.

Different amounts of dimethyl- $\beta$-cyclodextrin (DM- $\beta-C D)$ were adopted to protect against aggregation in the spray drying process during the manufacture of inhalable rhGH powder, and were tested in rats. ${ }^{72}$ One hundred micrograms of rhGH was insufflated through a polyethylene tube inserted into the trachea following incision between the fifth and sixth tracheal rings. Absolute bioavailabilities achieved 25.4\%, 76.5\%, and $64.0 \%$ of formulations containing rhGH: DM- $\beta-\mathrm{CD}$ at molar ratios of 10,100, and 1,000, respectively.

Pulmonary delivery is noninvasive, safe, and effective, and inhalable products of other drugs such as salmeterol xinafoate $\left(\right.$ Serevent ${ }^{\circledR}$, Diskus ${ }^{\circledR}$, GlaxoSmithKline, London, UK), and Budesonide (Pulmicort ${ }^{\circledR}$, Respules ${ }^{\circledR}$, Astrazeneca, London, UK) have demonstrated their efficacy for years. However, it is not perfect compared with other delivery methods. The dominant task is preparing uniform and lowdensity powders that can reach the lower respiratory tract and lung. This process may cause loss of rhGH particles and result in low bioavailability. In some cases, patients should be trained to obtain a special breath pattern to ensure the amount and accuracy of drug dose. Creating stable formulations can also be challenging. 


\section{Novel delivery devices}

Generally, there are five broad categories of devices: syringe with needle, injection pen, autoinjector pen, needle-free injector, and electronic injector. ${ }^{73}$

Conventional needles and syringes have inherent drawbacks, such as pain and inaccurate dosage. Routine injection also engenders needle phobia in GHD children. Smaller needles and preloaded drug made the injection less painful and accurate; automatic injection devices and invisible needles took a further step; and needle-free devices could be the least painful during injections with gas pressure. ${ }^{74,75}$

Zomajet $^{\circledR} 2$ Vision (Antares Pharma, Ewing, NJ, USA), Serojet ${ }^{\circledR}$ (EMD Serono, Inc. Rockland, MA, USA), and Norditropin NordiFlex ${ }^{\circledR}$ (Novo Nordisk, Bagsvaerd, Denmark) have already launched products which have been well accepted by patients. ${ }^{76,77}$ New devices like the Norditropin NordiFlex ${ }^{\circledR}$ Electronic needle-free device can be useful for all drugs administered via SC injection, but further development in terms of lowering the cost and minimizing pain is still necessary.

\section{Conclusion}

Given the long-term use of rhGH and the urgent need to improve compliance, the conventional needle and syringe are considered outdated. Different technologies and delivery routes have been investigated in the last two decades aiming to address this problem, and some accomplishments have already been put forward. Among the efforts, PLGA microspheres and novel injection devices seem to be the most successful; the former has been marketed then withdrawn due to manufacturing problems, and the latter is applied in clinical use and received better feedback over SC injection. Other methods show promise, though they present problems to be overcome.

To sum up, an impeccable delivery method should meet three critical requirements: 1) high delivery efficiency (high loading volume and bioavailability) considering the high daily dose of hGH required; 2) safety issues and an apparent improvement on compliance for the chronic diseases; and 3) feasibility for commercial use (avoiding problems in mass production).

\section{Acknowledgments}

The study was supported by National Science Foundation of China (Project No. 81373366, 81171203, 81171204 and 81200871, Shanghai Committee of Science and Technology, People's Republic of China (No. 11nm0503300, and 12XD1403800), and Funds for Interdisciplinary Projects of
Medicine and Engineering of Shanghai Jiao Tong University (No. YG2013MS52 and YG2013MS62).

\section{Disclosure}

The authors report no conflicts of interest in this work.

\section{References}

1. Strobl JS, Thomas MJ. Human growth hormone. Pharmacol Rev. 1994; 46(1):1-34.

2. Webster R, Xie R, Didier E, et al. PEGylation of somatropin (recombinant human growth hormone): impact on its clearance in humans. Xenobiotica. 2008;38(10):1340-1351.

3. Hermanussen M, Geiger-Benoit K, Sippell WG. Catch-up growth following transfer from three times weekly im to daily sc administration of hGH in GH deficient patients, monitored by knemometry. Acta Endocrinol (Copenh). 1985;109(2):163-168.

4. Kapoor RR, Burke SA, Sparrow SE, et al. Monitoring of concordance in growth hormone therapy. Arch Dis Child. 2008;93(2):147-148.

5. Ho KK; 2007 GH Deficiency Consensus Workshop Participants. Consensus guidelines for the diagnosis and treatment of adults with GH deficiency II: a statement of the GH Research Society in association with the European Society for Pediatric Endocrinology, Lawson Wilkins Society, European Society of Endocrinology, Japan Endocrine Society, and Endocrine Society of Australia. Eur J Endocrinol. 2007;157(6):695-700.

6. Laursen T, Gravholt CH, Heickendorff L, et al. Long-term effects of continuous subcutaneous infusion versus daily subcutaneous injections of growth hormone $(\mathrm{GH})$ on the insulin-like growth factor system, insulin sensitivity, body composition, and bone and lipoprotein metabolism in GH-deficient adults. J Clin Endocrinol Metab. 2001;86(3):1222-1228.

7. Giavoli C, Cappiello V, Porretti S, et al. Growth hormone therapy in GH-deficient adults: continuous vs alternate-days treatment. Horm Metab Res. 2003;35(9):557-561.

8. Reiter EO, Attie KM, Moshang T, et al; Genentech, Inc.-Alkermes, Inc. Collaborative Study Group. A multicenter study of the efficacy and safety of sustained release GH in the treatment of naive pediatric patients with GH deficiency. J Clin Endocrinol Metab. 2001;86(10):4700-4706.

9. Cunningham BC, Mulkerrin MG, Wells JA. Dimerization of human growth hormone by zinc. Science. 1991;253(5019):545-548.

10. Cunningham BC, Bass S, Fuh G, Wells JA. Zinc mediation of the binding of human growth hormone to the human prolactin receptor. Science. 1990;250(4988):1709-1712.

11. Johnson OL, Cleland JL, Lee HJ, et al. A month-long effect from a single injection of microencapsulated human growth hormone. Nat Med. 1996;2(7):795-799.

12. Herbert $\mathrm{P}$, Murphy $\mathrm{K}$, Johnson $\mathrm{O}$, et al. A large-scale process to produce microencapsulated proteins. Pharm Res. 1998;15(2):357-361.

13. Tracy MA. Development and scale-up of a microsphere protein delivery system. Biotechnol Prog. 1998;14(1):108-115.

14. Cawley P, Wilkinson I, Ross RJ. Developing long-acting growth hormone formulations. Clin Endocrinol (Oxf). 2013;79(3):305-309.

15. Kwak HH, Shim WS, Choi MK, et al. Development of a sustainedrelease recombinant human growth hormone formulation. J Control Release. 2009;137(2):160-165.

16. Johnson OL, Jaworowicz W, Cleland JL, et al. The stabilization and encapsulation of human growth hormone into biodegradable microspheres. Pharm Res. 1997;14(6):730-735.

17. Kim HK, Chung HJ, Park TG. Biodegradable polymeric microspheres with "open/closed" pores for sustained release of human growth hormone. J Control Release. 2006;112(2):167-174.

18. Vlugt-Wensink KD, de Vrueh R, Gresnigt MG, et al. Preclinical and clinical in vitro in vivo correlation of an hGH dextran microsphere formulation. Pharm Res. 2007;24(12):2239-2248. 
19. Lee HJ, Riley G, Johnson O, et al. In vivo characterization of sustainedrelease formulations of human growth hormone. J Pharmacol Exp Ther. 1997;281(3):1431-1439.

20. Wei Y, Wang Y-X, Wang W, Ho SV, Wei W, Ma G-H. mPEG-PLA microspheres with narrow size distribution increase the controlled release effect of recombinant human growth hormone. J Mater Chem. 2011;21(34):12691-12699.

21. Kakizawa Y, Nishio R, Hirano T, et al. Controlled release of protein drugs from newly developed amphiphilic polymer-based microparticles composed of nanoparticles. J Control Release. 2010;142(1):8-13.

22. Kim SJ, Hahn SK, Kim MJ, Kim DH, Lee YP. Development of a novel sustained release formulation of recombinant human growth hormone using sodium hyaluronate microparticles. J Control Release. 2005;104(2):323-335.

23. Péter F, Bidlingmaier M, Savoy C, Ji HJ, Saenger PH. Three-year efficacy and safety of LB03002, a once-weekly sustained-release growth hormone $(\mathrm{GH})$ preparation, in prepubertal children with $\mathrm{GH}$ deficiency (GHD). J Clin Endocrinol Metab. 2012;97(2):400-407.

24. Biller BM, Ji HJ, Ahn H, et al. Effects of once-weekly sustainedrelease growth hormone: a double-blind, placebo-controlled study in adult growth hormone deficiency. J Clin Endocrinol Metab. 2011;96(6):1718-1726.

25. Kelly CA, Howdle SM, Naylor A, et al. Stability of human growth hormone in supercritical carbon dioxide. J Pharm Sci. 2012 101(1):56-67.

26. Govardhan C, Khalaf N, Jung CW, et al. Novel long-acting crystal formulation of human growth hormone. Pharm Res. 2005; 22(9):1461-1470.

27. Kim HK, Park TG. Microencapsulation of human growth hormone within biodegradable polyester microspheres: protein aggregation stability and incomplete release mechanism. Biotechnol Bioeng. 1999;65(6):659-667.

28. Yoo HS. Photo-cross-linkable and thermo-responsive hydrogels containing chitosan and Pluronic for sustained release of human growth hormone (hGH). J Biomater Sci Polym Ed. 2007;18(11):1429-1441.

29. Katakam M, Ravis WR, Golden DL, Banga AK. Controlled release of human growth hormone following subcutaneous administration in dogs. Int J Pharm. 1997;152(1):53-58.

30. Tae G, Kornfield JA, Hubbell JA. Sustained release of human growth hormone from in situ forming hydrogels using self-assembly of fluoroalkyl-ended poly(ethylene glycol). Biomaterials. 2005;26(25): 5259-5266.

31. Shinde UP, Joo MK, Moon HJ, Jeong B. Sol-gel transition of PEGPAF aqueous solution and its application for hGH sustained release. J Mater Chem. 2012;22(13):6072-6079.

32. Park MR, Chun C, Ahn SW, Ki MH, Cho CS, Song SC. Sustained delivery of human growth hormone using a polyelectrolyte complexloaded thermosensitive polyphosphazene hydrogel. J Control Release. 2010;147(3):359-367.

33. Park MR, Seo BB, Song SC. Dual ionic interaction system based on polyelectrolyte complex and ionic, injectable, and thermosensitive hydrogel for sustained release of human growth hormone. Biomaterials. 2013;34(4):1327-1336.

34. Lee J, Tan CY, Lee SK, Kim YH, Lee KY. Controlled delivery of heat shock protein using an injectable microsphere/hydrogel combination system for the treatment of myocardial infarction. J Control Release. 2009;137(3):196-202.

35. Brodbeck KJ, Pushpala S, McHugh AJ. Sustained release of human growth hormone from PLGA solution depots. Pharm Res 1999;16(12):1825-1829.

36. García J, Dorta MJ, Munguía O, Llabrés M, Fariña JB. Biodegradable laminar implants for sustained release of recombinant human growth hormone. Biomaterials. 2002;23(24):4759-4764.

37. de Schepper J, Rasmussen MH, Gucev Z, Eliakim A, Battelino T. Longacting pegylated human $\mathrm{GH}$ in children with $\mathrm{GH}$ deficiency: a single-dose, dose-escalation trial investigating safety, tolerability, pharmacokinetics and pharmacodynamics. Eur J Endocrinol. 2011;165(3):401-409.
38. Clark R, Olson K, Fuh G, et al. Long-acting growth hormones produced by conjugation with polyethylene glycol. J Biol Chem. 1996; 271(36):21969-21977.

39. Cox GN, Rosendahl MS, Chlipala EA, Smith DJ, Carlson SJ, Doherty DH A long-acting, mono-PEGylated human growth hormone analog is a potent stimulator of weight gain and bone growth in hypophysectomized rats. Endocrinology. 2007;148(4):1590-1597.

40. Pasut G, Mero A, Caboi F, Scaramuzza S, Sollai L, Veronese FM. A new PEG-beta-alanine active derivative for releasable protein conjugation. Bioconjug Chem. 2008;19(12):2427-2431.

41. Magnusson JP, Bersani S, Salmaso S, Alexander C, Caliceti P. In situ growth of side-chain $\mathrm{PEG}$ polymers from functionalized human growth hormone-a new technique for preparation of enhanced protein-polymer conjugates. Bioconjug Chem. 2010;21(4):671-678.

42. Pai SS, Hammouda B, Hong K, Pozzo DC, Przybycien TM, Tilton RD. The conformation of the poly(ethylene glycol) chain in monoPEGylated lysozyme and mono-PEGylated human growth hormone. Bioconjug Chem. 2011;22(11):2317-2323.

43. Mero A, Schiavon M, Veronese FM, Pasut G. A new method to increase selectivity of transglutaminase mediated PEGylation of salmon calcitonin and human growth hormone. J Control Release. 2011;154(1):27-34.

44. Touraine P, D'Souza GA, Kourides I, et al; GH Lipoatrophy Study Group. Lipoatrophy in GH deficient patients treated with a long-acting pegylated GH. Eur J Endocrinol. 2009;161(4):533-540.

45. Poznansky MJ, Halford J, Taylor D. Growth hormone-albumin conjugates. Reduced renal toxicity and altered plasma clearance. FEBS Lett. 1988;239(1):18-22.

46. Osborn BL, Sekut L, Corcoran M, et al. Albutropin: a growth hormone-albumin fusion with improved pharmacokinetics and pharmacodynamics in rats and monkeys. Eur J Pharmacol. 2002;456(1-3): $149-158$.

47. Cleland JL, Geething NC, Moore JA, et al. A novel long-acting human growth hormone fusion protein (VRS-317): enhanced in vivo potency and half-life. J Pharm Sci. 2012;101(8):2744-2754.

48. Kim ES, Jang do S, Yang SY, et al. Controlled release of human growth hormone fused with a human hybrid $\mathrm{Fc}$ fragment through a nanoporous polymer membrane. Nanoscale. 2013;5(10):4262-4269.

49. Höybye C, Pfeiffer AFH, Ferone D, Gilfoyle D, Beckert M, Christiansen JS OR03-5 A phase 2, multicenter, multiple-dose, open-label, parallelgroup, active controlled, safety, tolerability, pharmacokinetic and pharmacodynamic study of ACP-001 in adult patients with Growth Hormone Deficiency (AGHD). Growth Horm IGF Res. 2012;22(Suppl 1): S8-S9.

50. Popovic V, Goth M, Vanuga P, et al. Once-weekly, CTP-modified hGH (MOD-4023) is effective in growth hormone deficient adults: a phase II, dose and frequency finding study. Presented at the 15th International and 14th European Congress of Endocrinology, Florence, Italy, May 5-9, 2012. Endocrine Abstracts. 2012;29:OC10.5.

51. Wilkinson IR, Ferrandis E, Artymiuk PJ, et al. A ligand-receptor fusion of growth hormone forms a dimer and is a potent long-acting agonist. Nat Med. 2007;13(9):1108-1113.

52. Baldwin PA, Klingbeil CK, Grimm CJ, Longenecker JP. The effect of sodium tauro-24,25-dihydrofusidate on the nasal absorption of human growth hormone in three animal models. Pharm Res. 1990;7(5):547-552.

53. Hedin L, Olsson B, Diczfalusy M, et al. Intranasal administration of human growth hormone $(\mathrm{hGH})$ in combination with a membrane permeation enhancer in patients with $\mathrm{GH}$ deficiency: a pharmacokinetic study. J Clin Endocrinol Metab. 1993;76(4):962-967.

54. Fisher AN, Farraj NF, O'Hagan DT, et al. Effect of 1- $\alpha-$ lysophosphatidylcholine on the nasal absorption of human growth hormone in three animal species. Int J Pharm. 1991;74(2-3): $147-156$.

55. Daugherty AL, Liggitt HD, McCabe JG, Moore JA, Patton JS. Absorption of recombinant methionyl-human growth hormone (Met-hGH) from rat nasal mucosa. Int J Pharm. 1988;45(3):197-206. 
56. Laursen T, Grandjean B, Jørgensen JO, Christiansen JS. Bioavailability and bioactivity of three different doses of nasal growth hormone $(\mathrm{GH})$ administered to GH-deficient patients: comparison with intravenous and subcutaneous administration. Eur $J$ Endocrinol. 1996;135(3):309-315.

57. Agerholm C, Bastholm L, Johansen PB, Nielsen MH, Elling F. Epithelial transport and bioavailability of intranasally administered human growth hormone formulated with the absorption enhancers didecanoylL-alpha-phosphatidylcholine and alpha-cyclodextrin in rabbits. J Pharm Sci. 1994;83(12):1706-1711.

58. Cheng YH, Dyer AM, Jabbal-Gill I, et al. Intranasal delivery of recombinant human growth hormone (somatropin) in sheep using chitosanbased powder formulations. Eur J Pharm Sci. 2005;26(1):9-15.

59. Aspden TJ, Illum L, Skaugrud $\varnothing$. Chitosan as a nasal delivery system: evaluation of insulin absorption enhancement and effect on nasal membrane integrity using rat models. Eur J Pharm Sci. 1996;4(1):23-31.

60. Steyn D, du Plessis L, Kotzé A. Nasal delivery of recombinant human growth hormone: in vivo evaluation with Pheroid technology and N-trimethyl chitosan chloride. J Pharm Pharm Sci. 2010;13(2):263-273.

61. Illum L, Farraj NF, Davis S, Johansen BR, O'Hagan DT. Investigation of the nasal absorption of biosynthetic human growth hormone in sheep - use of a bioadhesive microsphere delivery system. Int J Pharm. 1990;63(3):207-211.

62. Leitner VM, Guggi D, Krauland AH, Bernkop-Schnürch A. Nasal delivery of human growth hormone: in vitro and in vivo evaluation of a thiomer/glutathione microparticulate delivery system. J Control Release. 2004;100(1):87-95.

63. Levin G, Gershonowitz A, Sacks H, et al. Transdermal delivery of human growth hormone through RF-microchannels. Pharm Res. 2005;22(4):550-555.

64. Lee JW, Choi SO, Felner EI, Prausnitz MR. Dissolving microneedle patch for transdermal delivery of human growth hormone. Small. 2011; 7(4):531-539.

65. Fukushima K, Ise A, Morita H, et al. Two-layered dissolving microneedles for percutaneous delivery of peptide/protein drugs in rats. Pharm Res. 2011;28(1):7-21.

66. Ito Y, Ohashi Y, Shiroyama K, Sugioka N, Takada K. Self-dissolving micropiles for the percutaneous absorption of recombinant human growth hormone in rats. Biol Pharm Bull. 2008;31(8):1631-1633.

67. Folkesson HG, Hedin L, Weström BR. Lung to blood passage of human growth hormone after intratracheal instillation: stimulation of growth in hypophysectomized rats. J Endocrinol. 1992;134(2):197-203.

68. Patton JS, McCabe JG, Hansen SE, Daugherty AL. Absorption of human growth hormone from the rat lung. Biotechnol Ther. 1988;1(3):213-228.
69. Colthorpe P, Farr SJ, Smith IJ, Wyatt D, Taylor G. The influence of regional deposition on the pharmacokinetics of pulmonary-delivered human growth hormone in rabbits. Pharm Res. 1995;12(3):356-359.

70. Bosquillon C, Préat V, Vanbever R. Pulmonary delivery of growth hormone using dry powders and visualization of its local fate in rats. J Control Release. 2004;96(2):233-244.

71. Walvoord EC, de la Peña A, Park S, et al. Inhaled growth hormone $(\mathrm{GH})$ compared with subcutaneous $\mathrm{GH}$ in children with GH deficiency: pharmacokinetics, pharmacodynamics, and safety. J Clin Endocrinol Metab. 2009;94(6):2052-2059.

72. Jalalipour M, Najafabadi AR, Gilani K, Esmaily H, Tajerzadeh H. Effect of dimethyl-beta-cyclodextrin concentrations on the pulmonary delivery of recombinant human growth hormone dry powder in rats. $J$ Pharm Sci. 2008;97(12):5176-5185.

73. Yuen KC, Amin R. Developments in administration of growth hormone treatment: focus on Norditropin ${ }^{\circledR}$ Flexpro ${ }^{\circledR}$. Patient Prefer Adherence. 2011;5:117-124.

74. Fidotti E. A history of growth hormone injection devices. J Pediatr Endocrinol Metab. 2001;14(5):497-501.

75. Dahlgren J, Veimo D, Johansson L, Bech I. Patient acceptance of a novel electronic auto-injector device to administer recombinant human growth hormone: results from an open-label, user survey of everyday use. Curr Med Res Opin. 2007;23(7):1649-1655.

76. Cázares-Delgadillo J, Ganem-Rondero A, Kalia YN. Human growth hormone: new delivery systems, alternative routes of administration, and their pharmacological relevance. Eur J Pharm Biopharm. 2011;78(2):278-288.

77. Agersø H, Møller-Pedersen J, Cappi S, Thomann P, Jesussek B, Senderovitz T. Pharmacokinetics and pharmacodynamics of a new formulation of recombinant human growth hormone administered by ZomaJet 2 Vision, a new needle-free device, compared to subcutaneous administration using a conventional syringe. J Clin Pharmacol. 2002;42(11):1262-1268.

78. Kang J, Wu F, Cai Y, Xu M, Yuan W. Development of recombinant human growth hormone (rhGH) sustained-release microspheres by a novel low temperature aqueous phase/aqueous phase emulsion method. Eur J Pharm Sci. 2014;62:141-147.

79. Chantalat L, Jones ND, Korber F, Navaza J, Pavlovsky AG. The crystalstructure of wild-type growth-hormone at 2.5 angstrom resolution. Protein Pept Lett. 1995;2:333-340.
International Journal of Nanomedicine

\section{Publish your work in this journal}

The International Journal of Nanomedicine is an international, peerreviewed journal focusing on the application of nanotechnology in diagnostics, therapeutics, and drug delivery systems throughout the biomedical field. This journal is indexed on PubMed Central, MedLine, CAS, SciSearch ${ }^{\circledR}$, Current Contents ${ }^{\circledR} /$ Clinical Medicine,

\section{Dovepress}

Journal Citation Reports/Science Edition, EMBase, Scopus and the Elsevier Bibliographic databases. The manuscript management system is completely online and includes a very quick and fair peer-review system, which is all easy to use. Visit http://www.dovepress.com/ testimonials.php to read real quotes from published authors. 